\title{
Scanning Electron Microscopy and Molecular Characterization of Aedes albopictus (Skuse)
}

\author{
Soumendranath Chatterjee $\cdot$ Swapan Kumar Rudra • \\ Arunima Chakraborty • V. P. Sharma
}

Received: 10 April 2014/Revised: 23 July 2014/Accepted: 25 July 2014/Published online: 9 August 2014

(C) The National Academy of Sciences, India 2014

\begin{abstract}
Scanning electron microscopy and molecular characterization of Aedes albopictus larvae were done. Analysis of 28S rRNA gene sequence of Aedes albopictus Burdwan-SNC1 (KC208593) revealed comparatively higher GC content. Phylogenetic tree was prepared using the Neighbor-Joining (NJ) method. Phylogenetic tree revealed that Aedes albopictus Burdwan-SNC1 (KC208593) branched with the cluster containing of Aedes palauensis A26, Aedes hensilli A25, Aedes riversi A51A, Aedes dybasi A28, Aedes galloisi A77, Aedes flavopictus A47, Aedes albopictus A22, Aedes albopictus A34, Aedes albopictus MQSRNAGN and also branched with the cluster containing Aedes aegypti A20 and Aedes wadai A85. Scanning electron micrographs of Aedes albopictus larvae revealed that the structural complexity and number of both comb scales and pecten spines increased with larval growth and development. Similar results were revealed by anal papillae of abdominal segments.
\end{abstract}

Keywords Aedes albopictus.

Scanning electron microscopy $\cdot 28 \mathrm{~S}$ rRNA sequence Phylogenetic tree

S. Chatterjee $(\bowtie) \cdot$ A. Chakraborty

Parasitology and Microbiology Research Laboratory,

Department of Zoology, The University of Burdwan, Burdwan,

713 104, West Bengal, India

e-mail: soumen.microbiology@gmail.com

S. K. Rudra

Durgapur Government College, Durgapur, West Bengal, India

V. P. Sharma

Centre for Rural Development and Technology, Indian Institute of Technology, Hauz Khas, New Delhi 110016, India

\section{Introduction}

Majority of the mosquitoes are hematophagus in nature, which allows them to spread several pathogenic diseases. Among them one of the major public health concerns over the years is Dengue fever. Along with it, complications like Dengue hemorrhagic fever (DHF) and Dengue shock syndrome (DSS) have also posed tremendous threats. Dengue fever is a public health problem of global importance, producing a spectrum of disease spanning febrile arthralgia to hemorrhagic death. The burden of the disease is shocking worldwide. Dengue is an emerging infectious disease that is estimated to affect $50-100$ million individuals each year in tropical and subtropical areas [1]. Cases across the Americas, south-east Asia and western Pacific have exceeded 1.2 million cases in 2008 and over 2.3 million in 2010 (based on official data submitted by Member States of WHO). Recently the number of reported cases has continued to increase. In 2010, 1.6 million cases of dengue were reported in the Americas alone, of which 49,000 cases were severe dengue. In 2013, cases have occurred in Florida (United States of America) and Yunnan province of China. In Asia, Singapore has reported an increase in cases after a lapse of several years and outbreaks have also been reported in Laos. An estimated $5,00,000$ people with severe dengue require hospitalization each year, a large proportion of whom are children. According to WHO about $2.5 \%$ of the affected people die. Since 1967, many outbreaks of dengue have been investigated from India, with two major outbreaks reported from Delhi in 1996 and 2003 [2]. The 1996 outbreak was one of the largest one in Delhi, indicating a serious resurgence of the disease [3]. Gwalior, Madhya Pradesh, also saw a serious outbreak of febrile illness during October, 2003 to December, 2003 among which the major symptoms of 
patients included severe headache, fever, myalgia and vomiting etc [4]. Reports are available on the prevalence of Aedes aegypti throughout the year and Aedes albopictus in majority of the surveyed localities of Delhi with dengue virus infection in both Aedes aegypti and Aedes albopictus tested localities. This is the first report of dengue virus in Aedes albopictus from north India [5]. Another comprehensive study conducted in Kolkata suggested that dengue affected cases in 2012 outnumbered those of 2010 and 2011. Moreover it showed incidence within the age group of 11-30 years, with males being the target gender. Monsoon and post monsoon period showed the maximum of the dengue cases [6].

The vector of Dengue belongs to genus "Aedes" (Subfamily: Culicinae). Two important species Aedes aegypti and Aedes albopictus, are involved in the spread of DF/ DHF in north and south America, Africa, Europe [7-11] both of them are well adapted to breed in various artificial containers. Aedes albopictus is capable of breeding in a wide range of container types and water holding containers. General breeding sites, such as tree holes, coconut shells, fruit peels, water jars, earthen pots, cemented tanks, unused and discarded tyres, and old boats or cars holding water have been found to contain Aedes albopictus larvae [1214]. Certain areas showed the presence of both the species while sampling, which suggests convergent habitat segregation [15]. Present piece of work has been designed to determine the molecular characterization and Scanning Electron Microscopy of Aedes Albopictus third instar larva collected from rural areas of Burdwan with the aim to record the specific morphological features of Aedes albopictus larvae found in different localities of Burdwan as well as to determine the phylogenetic status of these mosquito species on the basis of 28S rRNA gene sequence alignment and phylogenetic tree construction to understand the bionomics of this vector species for effective control measures.

\section{Material and Methods}

Mosquito-Culture and Collection of Larva

Aedes albopictus third instar larvae were collected with the help of plankton net from various containers and tyres, cemented tanks, water logged areas with rain water in and around Burdwan district of West Bengal, India. Larvae were reared up to adult emergence in a mixture of breeding habitat water and tap water $(1: 1 \mathrm{v} / \mathrm{v})$ in white enamel trays at $27 \pm 1{ }^{\circ} \mathrm{C}$ and $80 \pm 5 \%$ relative humidity (RH) for 2-4 days. The larvae were fed on phyto- and zooplanktons during culture or experiments. The adults were maintained on honey soaked cotton pads at $27-28{ }^{\circ} \mathrm{C}$ and $80 \pm 5 \%$
RH in cages $\left(60 \mathrm{~cm}^{3}\right)$ in the Parasitology and Microbiology Research Laboratory, Department of Zoology, Burdwan University.

\section{Preparation of Scanning Electron Micrograph}

The third instar larvae were fixed in $2.5 \%$ Glutaraldehyde for $45 \mathrm{~min}$. The specimens were then dehydrated through graded alcohols $(50,70,90 \%)$ and finally with absolute alcohol for $10 \mathrm{~min}$. Finally they were subjected to critical point drying (C.P.D.). The specimens were gold coated and observed under scanning electron microscope. Measurements of different parts of larva were taken $[16,17]$.

\section{PCR Amplification and Sequencing of 28S rRNA Gene}

After isolation of DNA, PCR amplification of Ae. albopictus DNA was done. Using $28 \mathrm{~S}$ rRNA primers, the $\sim 400$ bp fragment was amplified using Taq DNA Polymerase. Universal primers were used. The PCR products were loaded on $1.5 \%$ agarose gel. The PCR conditions are as follows:

Step 1 At $94{ }^{\circ} \mathrm{C}$ for $5 \mathrm{~min}$ for one cycle

Step 2 At $94{ }^{\circ} \mathrm{C}-30 \mathrm{~s}$

Step 3 At $54{ }^{\circ} \mathrm{C}-35 \mathrm{~s}$ for 35 cycles

Step 4 At $72{ }^{\circ} \mathrm{C}$ for $30 \mathrm{~s}$

Step 5 At $72{ }^{\circ} \mathrm{C}$ for $10 \mathrm{~min}$

The PCR product was purified, bi-directionally sequenced and aligned.

Sequence Analysis and Phylogenetic Tree Preparation

Phylogenetic affiliation of the Ae. albopictus under study was done by $28 \mathrm{~S}$ rRNA gene sequence analysis. $28 \mathrm{~S}$ rRNA gene sequence was chosen for phylogenetic analysis because it is a evolutionary conserved sequence. Nucleotide BLAST (BLASTN) was done to investigate the most similar sequences from NCBI database. Aedes riversi, Aedes flavopictus have been described to date in the Ryuku Archipelago, Japan and their geographic distributions have been known to overlap. Aedes riversi and Aedes flavopictus are adapted to a forest environment whereas Aedes galliosi and Aedes wadai, which are a very rare group of species are confined more to the northern part of Japan [18]. Though these vectors cohabit domestic environments, still they have different roles in DHF/DF transmission [19]. Similarly Aedes hensili is responsible for transmission of Zika virus which was found from the blood of the people of Africa [20]. Aedes (Stegomyia) dybasi is an unique species, since it inhabits in pitchers of carnivorous plant, Nepenthes mirabilis Druce, as larval habitats. Traits of Ae. dybasi were compared with two sympatric, container-breeding 


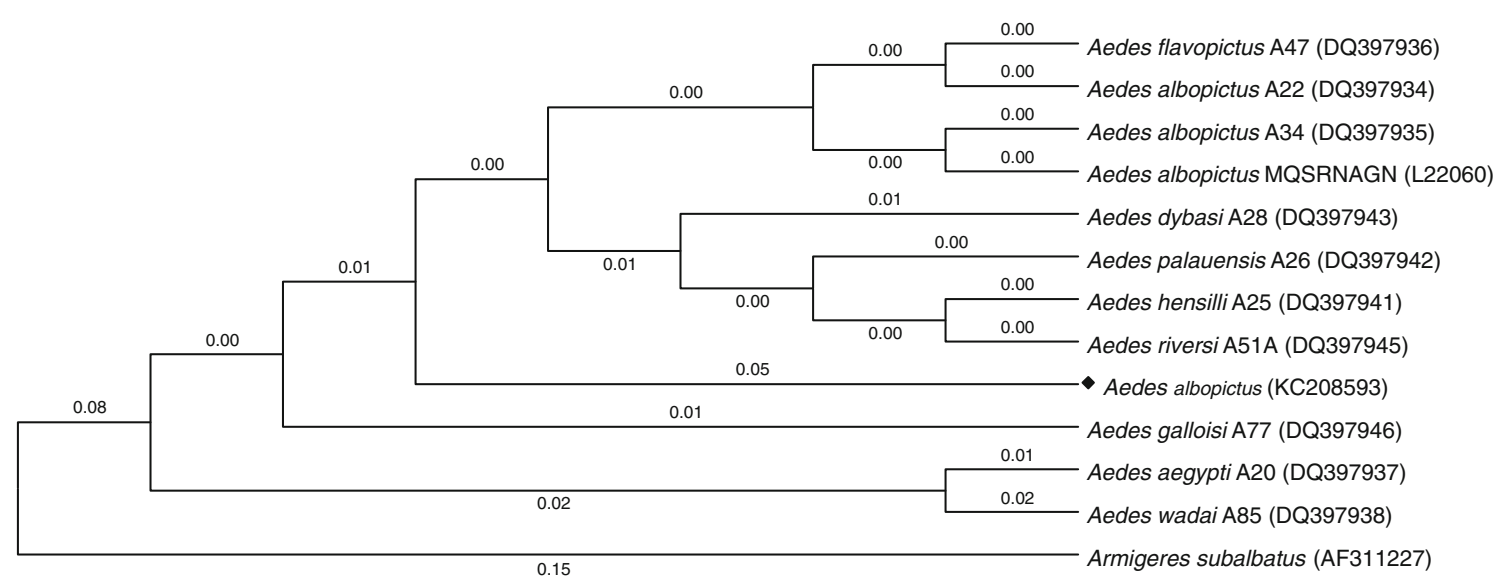

Fig. 1 Neighbor-joining tree constructed based on Aedes albopictus Burdwan-SNC1 (KC208593)28S ribosomal RNA partial gene sequence as reference sequence along with few other $28 \mathrm{~S}$ rRNA gene sequences retrieved from NCBI

Fig. 2 Restriction map of $28 \mathrm{~S}$ rRNA gene sequence of Aedes SNC 1 (KC208593) albopictus isolate Burdwan-

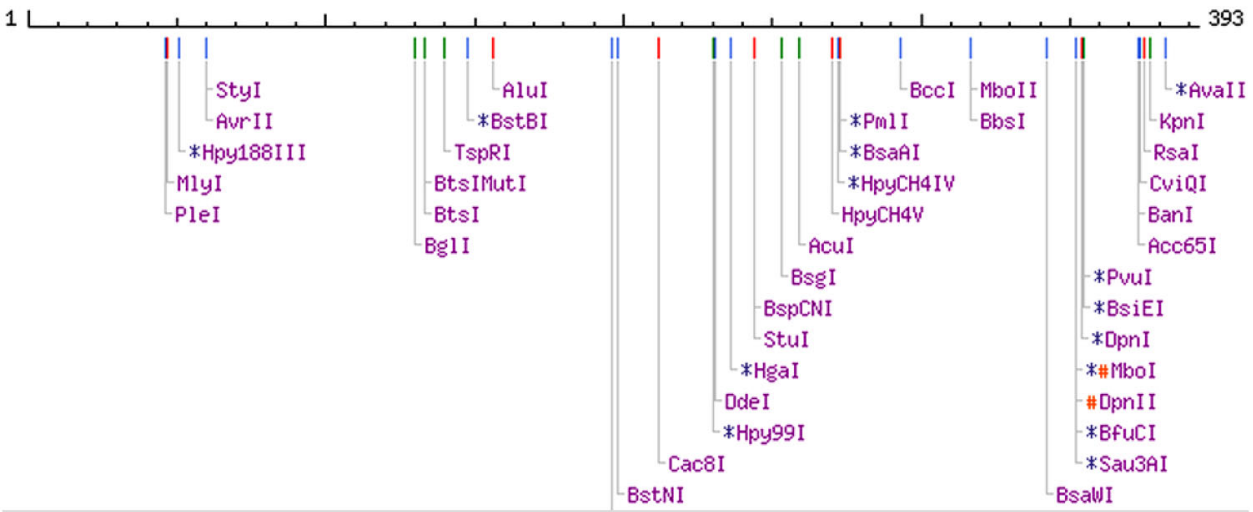

species, Aedes palauensis, a probable ancestor of Ae. $d y$ basi, and Aedes hensilli [21]. Phylogenetic tree was constructed taking those isolates which had the most similar sequences and which were ecologically relevant. The sequence data was aligned using the 'ClustalW Submission Form' and analyzed by ClustalW [22]. Evolutionary distances were calculated using the method of Jukes and Cantor [23] and the topology was inferred using the 'neighbor-joining' method [24]. 28S rRNA gene sequence of Armigeres subalbatus was taken as an out-group. To assign the taxonomical affiliation of Ae. albopictus, phylogenetic tree was prepared following Tamura et al. [25].

\section{Results and Discussion}

Analysis of 28S rRNA gene sequence of Ae. albopictus Burdwan-SNC1 (KC208593) revealed that it has higher GC content $(60.56 \%)$ than other isolates of Aedes flavopictus A47 (56.08\%), Aedes albopictus A34 (56.72\%), Aedes albopictus A22 (56.86 \%), Ae. albopictus MQSRNAGN (L22060) (52.45\%), Aedes palauensis A26 (56.54\%), Aedes hensilli A25 (56.82\%), Aedes riversi

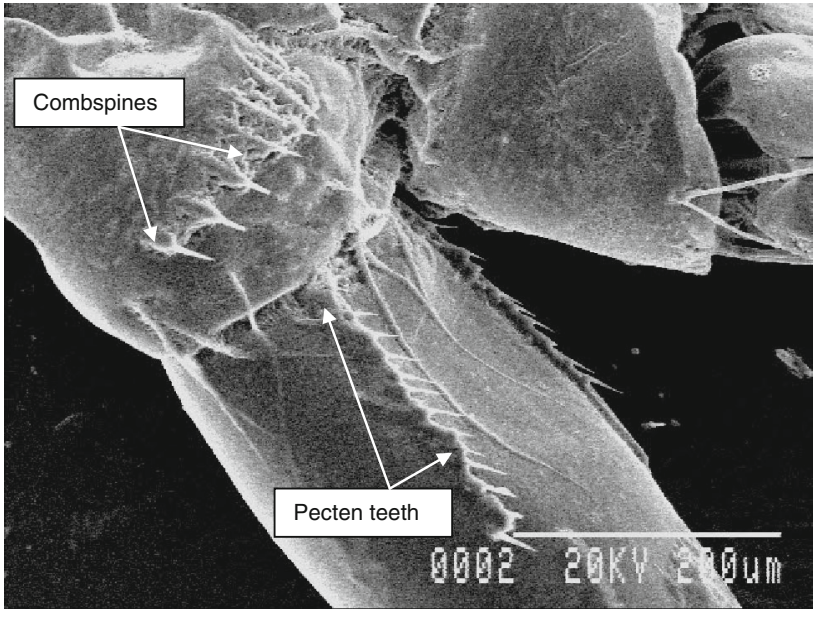

Fig. 3 VIII abdominal segment of 3rd instar larva of Aedes albopictus showing comb scales and pecten teeth

A51A (56.665 \%), Aedes dybasi A28 (56.86\%), Aedes aegypti A20 (56.36), Aedes galloisi A77 (56.55 \%), Aedes wadai A85 (56.75\%). AT content of Aedes albopictus Burdwan-SNC1 (KC208593) was found to be $39.44 \%$. Taking Aedes albopictus Burdwan-SNC1 (KC208593) 


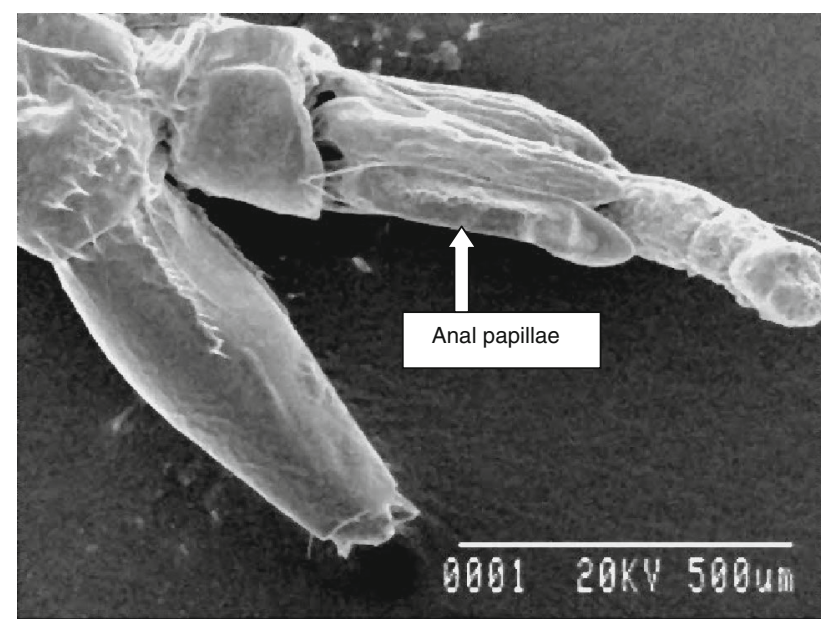

Fig. 4 VIII abdominal segment of 3rd instar larva of Aedes albopictus showing anal papillae

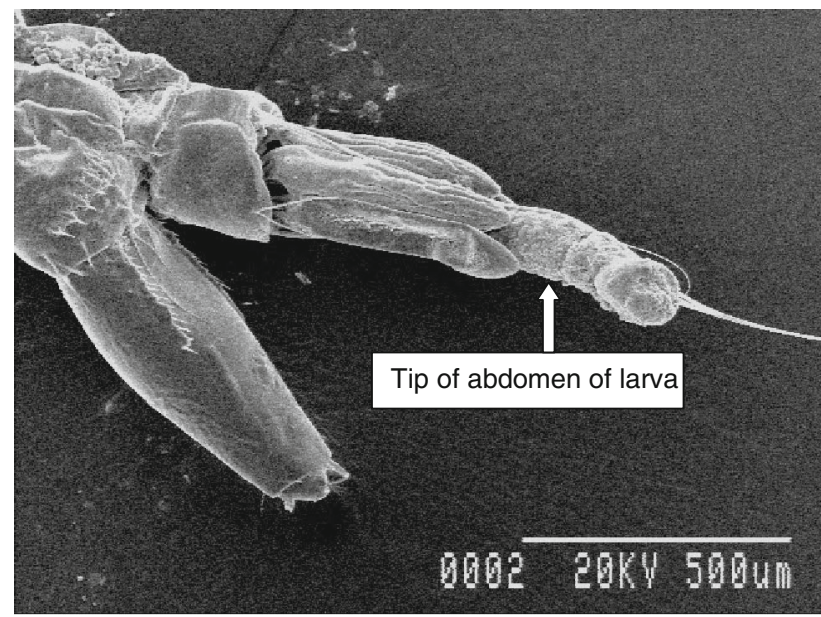

Fig. 5 VIII abdominal segment of 3rd instar larva of Aedes albopictus showing tips of the abdomen, spiracles, anal papillae

$28 \mathrm{~S}$ rRNA gene sequence as reference sequence, the phylogenetic tree was prepared and displayed in Fig. 1. The phylogenetic tree analysis showed that Aedes albopictus Burdwan-SNC1 (KC208593) branched with the cluster containing Aedes palauensis A26, Aedes hensilli A25, Aedes riversi A51A, Aedes dybasi A28, Aedes galloisi A77, Aedes flavopictus A47, Aedes albopictus A22, Aedes albopictus A34, Aedes albopictus MQSRNAGN (Fig. 2) and also branched with the cluster containing Aedes aegypti A20 and Aedes wadai (A85). The branch lengths have also been shown. The Restriction enzyme map on the 28SrRNA nucleotide sequence of Aedes albopictus Burdwan-SNC1 (KC208593) has been shown in Fig. 2.

Scanning electron micrographs of Ae. albopictus larva have been shown in Figs. 3, 4 and 5. It has been revealed that the structural complexity and the number of comb scales was positively correlated with the development and instar of the larva. As also noticed by Stefan and Francisco [26] the number of comb scales varied in different instars as well as in different specimens collected from different areas. Usually the comb scales were four in number in the 1st instar larvae while six to seven were recorded from the 3rd instar larvae of the collected specimens (Fig. 3). They are arranged in a row in first instar, gradually achieving a semilunar pattern while developing from 1st to 4th larval instar. Each of the comb spines has a long median denticle (close to the siphon) and subapical denticles having pointed tips (Fig. 3). The respiratory siphon bears a row of pecten teeth on both sides and basal denticles. They are arranged in a row orienting towards the spiracle. The spines proximal to the spiracle are usually longer and the distal ones are comparatively smaller. The number of pecten teeth showed an increase in successive instars [26]. Their number in the 3rd instar larva varies from 12 to 13 . The denticles of the pecten teeth are variable in size in every larval stage. At the terminal portion of the Ae. albopictus larva is the anal segment (Figs. 4, 5). Anal papillae are seen on the anal segment. Three anal papillae of more or less equal size were seen in all the larval instars which also gradually increased in length with successive larval duration and development.

\section{Conclusion}

Scanning Electron micrograph of the larval stage of Aedes albopictus revealed the structural peculiarity of this vector and showed that both comb scales and pecten spines were increased in number with the development and growth of larva. 28S rRNA gene sequence revealed the higher GC content of this species occurring in Burdwan which reflects the regional specificity of these vectors. Phylogenetic tree clearly reveals that this species branched with other Aedes spp which have great medical importance in different regions of the world.

Acknowledgments The authors are grateful to the Department of Environment (D.O.E.), Govt. of West Bengal for financial assistance.

\section{References}

1. Halstead SB (2007) Dengue. Lancet 370:1644-1652

2. Gupta E, Dhar L, Narang P, Srivastava VK, Broor S (2005) Serodiagnosis of dengue during an outbreak at a tertiary carehospital in Delhi. Indian J Med Res 121:36-38

3. Lall R, Dhanda V (1996) Dengue haemorrhagic fever and the dengue shock syndrome in India. Natl Med J India 9:20-23

4. Dash PK, Saxena P, Abhyankar A, Bhargava R, Jana AM (2005) Emergence of dengue virus type-3 in Northern India. Southeast Asian J Trop Med Public Health 36(2):370-377 
5. Kumari R, Kumar K, Chauhan LS (2011) First dengue virus detection in Aedes albopictus from Delhi, India: its breeding ecology and role in dengue transmission. Trop Med Int Health 16(8):949-954

6. Bandopadhyaya B, Bhattacharyya I, Adhikary S et al (2013) A comprehensive study on the 2012 dengue fever outbreak in Kolkata, India. ISRN Virol, Volume 2013, Article ID 207580

7. Gratz NG (1967) The control of Ae. aegypti In South-East Asia and the Western Pacific. Bull Org mond Sante 36:614-617

8. Gubler DJ (1998) Dengue and dengue haemorrhagic fever. Clin Microbiol Rev 11:480-496

9. Guzman MG, Kouri G (2002) Dengue: an update. Lancet Infect Dis 2:33-42

10. Mitchell CJ (1995) The role of Aedes albopictus as an arbovirus vector. Parasitologia 37:109-111

11. Porter AG, Davidson EW, Liu JW (1993) Moisquitocidal toxins of bacilli and their genetic manipulation for effective biological control of mosquitoes. Microbial Rev 57:838-861

12. Ansari MA, Razdan RK (1998) Seasonal prevalence of $A e$ desaegypti in five localities of Delhi, India. Dengue Bulletin 22:28-32

13. Thavara U, Tawatsin A, Chompoosri J (2004) Evaluation of attractants and egg-laying substrate preference for oviposition by Aedesalbopictus (Diptera: Culicidae). J Vector Ecol 29(1):66-72

14. Wongkoon S, Jaroensutasinee M, Jaroensutasinee K (2005) Larval infestation of Aedesaegypti and Ae.albopictus in Nakhon Si Thammarat, Thailand. Dengue Bull 29:169-175

15. Simard F, Nchoutpouen E, Toto JC, Fontenille D (2005) Geographic distribution and breeding site preference of Aedesalbopictus and Aedesaegypti (Diptera: culicidae) in Cameroon, Central Africa. J Med Entomol 42(5):726-731

16. Glauert AM (1975) Fixation methods. In: Glauert AM (ed) Fixation, dehydration and embedding of biological specimens. North-Holland Publishing Company, Amsterdam, pp 73-110 (3rd printing 1980)
17. Glauert AM (1975) Dehydration. In: GlauertAM (ed) Fixation, dehydration and embedding of biological specimens. NorthHolland Publishing Company, Amsterdam, pp 111-122 (3rd printing 1980)

18. Tanaka K, Mizusawa K, Saugstad ES (1979) A revision of the adult and larval mosquitoes of Japan (including the Ryuku Archipelago and Ogasawara islands) and Korea (Diptera: Culicidae). Contrib Am Entomol Inst 16:1-987

19. HigaY Nguyen TY, Kawada H et al (2010) Geographic distribution of Aedesaegypti and Aedesalbopictus (Diptera: Culicidae) from used tires in Vietnam. J Am Mosq Control Assoc 23:1-9

20. Bel M (2007) Preliminary report of Zika virus outbreak in yap. Inform' action no 27.https://www.spc.int/phs/index2.php?option= com_docman\&task=doc_view\&gid $=682 \&$ Itemid $=102$. Accessed Sep 2007

21. Mogi M (2010) Unusual life history traits of Aedes (Stegomyia) mosquitoes (Diptera: Culicidae) inhabiting nepenthes pitchers. Ann Entomol Soc Am 103(4):618-624

22. Thompson JD, Higgins DG, Gibson TJ (1994) CLUSTAL W: improving the sensitivity of progressive multiple sequence alignment through sequence weighting, position-specific gap penalties and weight matrix choice. Nucleic Acids Res 22(22):4673-4680

23. Jukes TH, Cantor CR (1969) Evolution of protein molecules. In: Munro HN (ed) Mammalian protein metabolism. Academic Press, New York, pp 21-132

24. Saitou N, Nei M (1987) The neighbor-joining method: a new method for reconstructing phylogenetic trees. Mol Bio Evol 4(4):406-425

25. Tamura K, Dudley J, Nei M, Kumar S (2007) MEGA4: molecular evolutionary genetics analysis (MEGA) software version 4.0. Mol Biol Evol 24:1596-1599

26. Stefan S, Hernández-Chavarría Francisco (2006) Scanning electron microscopy of the four larval instars of the Dengue fever vector Aedes aegypti (Diptera: Culicidae). Rev Biol Trop 54(3):843-846 